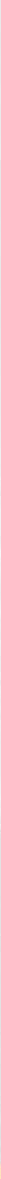

VOL. 5 | N.9 | JAN/JUN DE 2019 | ISSN 2359-4489

MÚLTIPLOS OLHARES

SOBRE POLITICA

E RELIGĨ̃O 


\title{
Mulher, política e religião:
}

o puritanismo por Emma Goldman

\section{Nilciana Alves Martins}

ORCID: 0000-0002-7337-5394

Mestranda em História pelo Programa de Pós-Graduação em História da

Universidade Federal de Juiz de Fora. E-mail: nilcianaalves@gmail.com

\section{Resumo}

O presente trabalho, além de fazer um resgate da trajetória biográfica de Emma Goldman, busca, principalmente, investigar seu artigo intitulado "The Hypocrisy of Puritanism” (1910) e, nesse sentido, compreender qual era, na visão de Goldman, o papel do puritanismo na definição e/ou legitimação de quais práticas cotidianas seriam ditas como positivas, isto é, na criação de regras de conduta socialmente aceitas e estimuladas por uma dada sociedade. Além disso, pretende-se entender qual era, segundo Goldman, a capacidade de inserção do puritanismo na arte, na política, bem como na vida das mulheres, obviamente, isto em sociedades marcadas por uma cultura na qual tal concepção, ou seja, o puritanismo se fez presente.

Palavras-chaves: Emma Goldman; Puritanismo; Política e Religião.

\section{Women, politics and religion:}

puritanism by Emma Goldman

\begin{abstract}
The present work, in addition to making a rescue of the biographical trajectory of Emma Goldman, mainly seeks to investigate his article entitled "The Hypocrisy of Puritanism" (1910) and, in this sense, to understand what was, in Goldman's view, the role of Puritanism in the definition and / or legitimation of what daily practices would be said to be positive, that is, in the creation of rules of conduct socially accepted and stimulated by a given society. In addition, it is intended to understand what, according to Goldman, was the capacity for
\end{abstract}


insertion of Puritanism in art, politics, and women's lives, obviously in societies marked by a culture in which such a conception, that is, the Puritanism was present.

Keywords: Emma Goldman; Puritanism; Politics and Religion.

\title{
Um breve panorama biográfico ${ }^{1}$
}

Em meio ao governo de Alexandre II, mais especificamente em junho de 1869, nasce na região de Kovno (hoje Kaunas) na Lituânia, a figura de Emma Goldman. Na época de seu nascimento seus pais Taube Biendvitch e Abraham Goldman, mesmo sendo judeus, gozavam de relativa tranquilidade - devido às medidas oriundas do governo de Alexandre II - mas, ainda sim, passavam por dificuldades financeiras. Nunca tiveram muito, mas a família encontrava-se em uma situação mais delicada, pois a "má sorte fez Abraham perder, nos negócios, a herança que Taube trouxera de seu primeiro casamento"². Abraham esperava não por uma filha, mas por um varão, condição que dificultou a relação dele com E. $\mathrm{G}^{3}$.

\begin{abstract}
Emma nació en 1869 , en un gueto en la Rusia zarista. Su padre, cuya furia y cuyos golpes recordó siempre como 'la pesadilla de mi infancia', se quejaba continuamente de que su primogénito hubiera sido una niña. Su madre vigiló su educación sexual con tradicional rigor. No solamente la amenazó y la castigó cuando se 'tocaba', sino que además, al descubrir que Emma había comenzado a menstruar a la edad de once años, le dio una bofetada y le explicó: 'Es lo que necesita una joven cuando se convierte en mujer, como protección contra la desgracia'. El castigo produjo en la niña una fuerte y duradera impresión. ${ }^{4}$
\end{abstract}

Aos oitos anos, E.G. foi morar com a avó e tios em Konigsberg, com o objetivo de estudar em uma escola alemã. Entretanto, com a viagem da avó, seus tios a tratavam como escrava doméstica, o que dificultava seus estudos. Na instituição familiar, E.G. era considerada um ser inferior, assim também era na instituição escolar. Professores abusivos e autoritários, mas, no meio do caos, uma professora alemã adorável, que marcou profundamente Goldman. Superando as dificuldades, E.G. conseguiu ser aprovada no exame para Gymnasium, entretanto, precisava de um certificado de boa conduta, que foi negado pelo professor de religião, mesmo homem que batia com réguas nas meninas da classe.

\footnotetext{
${ }^{1}$ Saiba mais sobre a trajetória de Emma Goldman em: GOLDMAN, Emma. "Vivendo minha Vida". Curitiba: L-Dopa Publicações, 2015.

${ }^{2}$ LOBO, Elisabeth Souza. "Emma Goldman — A vida como Revolução". São Paulo, Brasiliense, 1983.p.12.

${ }^{3}$ A partir de agora trataremos Emma Goldman pela sigla "E.G.".

${ }^{4}$ Fragmento retirado do prólogo - escrito por Alix Kates Shulman - da obra: BIANCHI, Bruna (epílogo) \& SHULAMAN. Alix Kates (prólogo). GOLDMAN, Emma. "La mujer más peligrosa del mundo: textos feministas de Emma Goldman”. Edición: La Congregación [Anarquismo em PDF], Portada: Reybum. 8p.
} 
No ano de 1881, com a morte do czar e o aumento do antissemitismo, a família Goldman se transfere para São Petersburgo e, com isso, a jovem interrompeu seus estudos, pois começou a trabalhar em uma fábrica de espartilhos, para ajudar nas finanças da família. $\mathrm{Na}$ Capital, E.G. teve contato mais direto com as obras niilistas - já que sua irmã Helena havia conseguido acesso a algumas obras por meio de estudantes da época ${ }^{5}$ - e com os discursos sobre as personagens revolucionárias, isto é, sobre o papel das mulheres russas nas revoltas populares, obter esse conhecimento influenciou significativamente na trajetória de Goldman.

Era el año 1882; el Zar había sido asesinado y la revolución flotaba en el aire de Petersburgo. Allí, la ya rebelde Emma supo que en Rusia había mujeres revolucionarias que vivían para sí mismas y para la revolución, no para sus hombres. Esas mujeres ansiaban incluso ser mártires por la causa en la que creían, y eran absolutamente diferentes de las otras mujeres que Emma había conocido. Las convirtió en su modelo —en sus ídolos—y se sumó a su feminismo. ${ }^{6}$

No ano de 1886, E.G. resolveu acompanhar Helena - que planejava encontrar sua outra irmã, Lena, que estava em território norte-americano. Com isso, no mês de dezembro do mesmo ano, as irmãs imigraram para os Estados Unidos da América, em busca de melhores condições de vida na "terra prometida".

Ao chegar aos Estados Unidos da América, E.G. trabalhou em diferentes empresas o que, em certo sentido, aproximou a jovem da causa operária. Mas, foram a Revolta de Hayamarket $^{7}$ (1886) e o movimento dos Metalúrgicos de Homestead ${ }^{8}$ os eventos que, devido ao grande impacto que tiveram na vida de Emma Goldman, fizeram crescer na jovem a

${ }^{5}$ GOLDMAN, Emma. "Vivendo minha Vida". Curitiba: L-Dopa Publicações, 2015. p.22.

${ }^{6}$ Fragmento retirado do prólogo - escrito por Alix Kates Shulman - da obra: BIANCHI, Bruna (epílogo) \& SHULAMAN. Alix Kates (prólogo). GOLDMAN, Emma. "La mujer más peligrosa del mundo: textos feministas de Emma Goldman”. Edición: La Congregación [Anarquismo em PDF], Portada: Reybum. 8p.

${ }^{7}$ Considerada como uma das origens do dia do trabalhador, a Revolta de Haymarket, que ocorreu em Chicago (1886), diz de manifestações populares que reivindicavam melhores condições para os trabalhadores, entre as pautas, estava à jornada por oito horas de trabalho. A referida revolta foi severamente reprimida pelo Estado, deixando vários mortos e feridos. Entre as pessoas presas, estavam oito anarquistas, acusados de terem lançado, durante a manifestação, um artifício explosivo. Entretanto, não existiam provas que legitimassem a referida acusação, por isso, iniciou-se uma campanha pela libertação desses anarquistas, que ficaram conhecidos como "Os mártires de Chicago". Alguns desses socialistas libertários foram condenados à forca e, outros, a prisão. A revolta, assim como a forma que a opinião pública acusava esses "mártires", fez com que E.G. optasse por dar continuidade à luta desses militantes, isto é, tal evento contribuiu significativamente para que Goldman se aproximasse do movimento anarquista da época, como é possível verificar em sua autobiografia. Sobre a referida revolta ver mais em: Avrich, Paul. "The Haymarket Tragedy". Princeton: Princeton University Press, 1986.

${ }^{8}$ Movimentação dos trabalhadores de Homestead (1892) contra as medidas arbitrárias - intensificadas pelo diretor Henry Clay Frick - e as péssimas condições as quais estavam submetidos, ao prestarem serviços para Companhia Carnegie Steel. E.G. participou ativamente deste movimento. Sobre esse movimento ver mais em: KRAUSE, Paul. "The battle for Homestead, 1880-1892: politics, culture, and steel". Pittsburgh: University of Pittsburgh Press, 1992. 584 p. 
vontade de se aproximar do círculo anarquista norte-americano. Inicialmente, Goldman entrou em contato com Johan Most ${ }^{9}$, até então diretor do jornal Die Freiheit e, graças ao estímulo de Most, E.G. iniciou uma série de palestras sobre a jornada por oito horas de trabalho. Como sabemos hoje, era o início de sua carreira como propagandista do anarquismo. Entretanto, posteriormente, E.G. se aproximou do periódico Die Autonomie, pois, nas palavras da própria: "seus princípios eram mais próximos do que o anarquismo havia passado a significar para mim, mais do que os do Freiheit. O Autonomie enfatizava mais a liberdade do indivíduo e a independência dos grupos"10.

Em pouco tempo E.G. tornou-se uma figura pública, especialmente devido a sua intensa participação em movimentos que se colocavam contra os diferentes tipos de opressão às quais as camadas subalternas estavam submetidas naquele contexto. Goldman atuou em greves, realizou inúmeras palestras sobre o anarquismo - bem como sobre outros temas - e foi uma militante ativa a favor da emancipação das mulheres. Todas essas atividades fizeram com que, Goldman, fosse taxada, pela grande mídia, como uma "mulher perigosa" $" 11$ e, com isso, ela foi perseguida e aprisionada inúmeras vezes, isto, claro, devido sua atuação na luta contra as opressões de classe e de gênero.

Em 1906, E.G. fundou a revista Mother Earth, que funcionou até o ano de 1917, momento no qual ela - junto com seu companheiro Alexandre Berkman ${ }^{12}$ - foi deportada para a Rússia. Goldman não só participou de importantes eventos históricos, como, por exemplo, o processo revolucionário russo e a Revolução Espanhola, como também desenvolveu uma série de interpretações sobre esses eventos. Nesse sentido, além de militante anarquista e feminista, E.G. foi, simultaneamente, uma grande intelectual que produziu uma literatura, produziu interpretações teóricas repletas de especificidades. Mas, ainda sim, como aponta Bruna Bianchi, a maioria dos estudos biográficos sobre Goldman negligenciaram sua

\footnotetext{
${ }^{9}$ Sobre o personagem ver: http://www.anarquista.net/johann-most/. Acesso 05/01/2018.

${ }^{10}$ GOLDMAN, Emma. "Vivendo minha Vida". Curitiba: L-Dopa Publicações, 2015. p.57.

${ }^{11}$ Ver mais em: LOBO, Elisabeth Souza. "Emma Goldman - A vida como Revolução". São Paulo, Brasiliense, 1983.

${ }^{12}$ Alexander Berkman (1870-1936) foi um anarquista de origem russa que emigrou para os Estados Unidos em 1888, onde se envolveu diretamente no movimento anarquista. Foi amante e companheiro de luta de Emma Goldman. Durante sua trajetória nos EUA foi preso, sob a acusação de ter tentado assassinar Henry Clay Frick. Ainda nos Estados Unidos participou do periódico "Mother Earth" e fundou o "The Blast". Em 1917, Berkman e Goldman são sentenciados a dois anos de prisão por serem contra o alistamento obrigatório. Em 1919, ambos são deportados chegando a território russo no mesmo ano. Em 1925, Berkman publicou a obra "O Mito Bolchevique", além disso, foi autor do livro "O ABC do anarcocomunismo". Em 1936, Berkman comete suicídio. Ver: http://www.anarquista.net/alexander-berkman/. Acesso 15/10/17.
} 
contribuição teórica considerando-a muitas vezes "como una divulgadora de las teorías de los demás, en particular de Bakunin y de Kropotkin"13.

Rompendo com essa historiografia tradicional, ou seja, com essa perspectiva que não se atenta para a contribuição teórica de E.G., e, além disso, investigando a produção de nossa personagem, é possível perceber que em seus escritos, Goldman trabalhava temas como a liberdade sexual, o tráfico de mulheres, prostituição e homossexualidade, sempre deixando visível sua perspectiva socialista libertária. Ao falar sobre o pensamento intelectual de E.G., Margareth Rago, aponta que:

em diferentes frentes de ataque à exploração capitalista, ao imperialismo e à opressão de gênero, ousa discutir assuntos até então pouco enunciados por mulheres, mesmo entre as feministas. O tráfico das 'escravas brancas', a prostituição, o casamento e o amor livre compõem um conjunto desses ${ }^{14}$.

Ademais, segundo Thaddeus Blanchette:

A continuada importância do pensamento de Goldman é fruto de sua visão pouco ortodoxa das lutas políticas e culturais de seu tempo. Enquanto muitos de seus contemporâneos acreditavam em modelos ideológicos que pregavam o autoritarismo em nome da construção de uma sociedade ideal, —Emma Vermelhall duvidava de qualquer filosofia que louvasse a repressão. Embora fosse uma anarquista que não desprezava a violência como ferramenta revolucionária [...] Goldman nunca endeusou qualquer ideologia a ponto de perder de vista as políticas cotidianas que Foucault, mais tarde, rotularia de controle e disciplina. Não só se preocupava com a luta de classes e as políticas de massa, como também enxergava as inúmeras maneiras com que o poder invade a vida cotidiana, condicionando mentes, corpos e almas. $^{15}$

Dito isso, o presente trabalho busca investigar o artigo "The Hypocrisy of Puritanism" escrito por E.G. e publicado inicialmente na Mother Earth e, posteriormente, no livro "Anarchism and Other Essays". Busca-se, nesse sentido, perceber quais relações que E.G. traça entre o puritanismo e outras esferas da vida social tais como: a arte, a política, a vida cotidiana, entre outras.

\section{A força do puritanismo: um breve resgaste histórico}

\footnotetext{
${ }^{13}$ BIANCHI, Bruna (epílogo); SHULAMAN. Alix Kates (prólogo). GOLDMAN, Emma. “La mujer más peligrosa del mundo: textos feministas de Emma Goldman". Edición: LaCongregación [Anarquismo em PDF], Portada: Reybum, 2009.

${ }^{14}$ RAGO, Margareth. "Prefácio à Emma Goldman: tráfico de Mulheres". Cad. Pagu [online]. 2011, n.37, pp.263-271. ISSN 0104-8333. http://dx.doi.org/10.1590/S0104-83332011000200010. Acesso: 12/11/2017.

${ }^{15}$ BLANCHETTE, Thaddeus. "Emma Vermelha e o espectro do tráfico de mulheres". Cad. Pagu [online]. 2011, n.37, pp. 284-297. ISSN 0104-8333. Disponível em: http://dx.doi.org/10.1590/S010483332011000200012. Acesso 10/06/2018.
} 
Se somos sábios, não tenhamos confiança alguma em nós mesmos e coloquemos confiança no poder preservador de Deus (John Owen).

Desde o começo a fé cristã é sacrifício: sacrifício de toda liberdade, todo orgulho, toda confiança do espírito em si mesmo. (Friedrich Nietzsche) ${ }^{16}$.

A colonização dos Estados Unidos da América (iniciada no século XVII) possui uma relação direta com a situação na qual se encontrava a Inglaterra desde o século XV. Nesse sentindo, características que marcavam a situação interna da Inglaterra explicam a negligência que o país teve em relação às treze colônias. No século XV, na Inglaterra, teve-se início um processo denominado "cercamento dos campos" ${ }^{17}$ que - além de produzir uma série de consequências de longa-duração -, significou a expropriação do campesinato e, consequentemente, a intensificação do processo de monopolização dos meios de produção. E, com isso, esses camponeses migraram forçadamente para os centros urbanos onde foram, por conseguinte, obrigados a vender sua força produtiva para sobreviver. Entretanto, nem todos são absorvidos pelo mercado de trabalho, surgindo um vasto excedente de mão-de-obra.

Diante desse excedente de mão-de-obra ${ }^{18} \mathrm{e}$, em certo sentido, com o intuito de desenvolver nesses antigos camponeses um comportamento "político cultural” exigido pelo Capital ${ }^{19}$ - afinal, era o início da "ditadura do relógio" 20 - o Estado inglês criou uma série de medidas autoritárias, entre as quais está as Leis Contra a Vagabundagem. Sobre as consequências do processo de expropriação dos camponeses, Peter Linenbaugh e Marcus Rediker acrescentam que: "Na Inglaterra, a expropriação do campesinato foi acompanhada de violência e terror sistemáticos, na forma de penas criminais, buscas públicas, prisões, lei marcial, pena de morte, desterro, trabalhos forçados e colonização". ${ }^{21}$

Essas expropriações convergiram com o processo de colonização fazendo com que a Inglaterra, diferentemente do que ocorreu com Portugal e Espanha, tivesse uma gigantesca e desesperada população para ser transferida para o Novo Mundo. Segundo Peter Linenbaugh e Marcus Rediker:

\footnotetext{
${ }^{16}$ NIETZSCHE, Friedrich. "Além do bem e do mal”. São Paulo, Companhia de Bolso, 2005, p.48.

${ }^{17}$ Ver mais em: MARX, Karl. "A Origem do Capital: a acumulação primitiva". São Paulo: Editora Global, 1977.

${ }^{18}$ Sobre o fenômeno do excedente de mão-de-obra ver escritos do Karl Marx, bem como a produção de Marcus Rediker e Peter Linenbaugh.

19 Sobre a mudança cultural que marca esse contexto ver mais nos escritos do historiador britânico E. P.. Thompson (1924-1993).

${ }^{20}$ Sobre o conceito ver artigo “A ditadura do relógio" de George Woodcock.

${ }^{21}$ LINENBAUGH, Peter; REDIKER, Marcus. "A hidra de muitas cabeças: marinheiros, escravos, plebeus e a história oculta do Atlântico revolucionário". São Paulo: Companhia das Letras, 2008, p.60.
} 
As expropriações que coincidiram com a colonização significavam que a Inglaterra, diferentemente de Portugal, Espanha, Holanda ou França, tinha uma imensa e desesperada população que poderia ser transferida para além-mar. ${ }^{22}$

John Donne prometeu num sermão em 1622 que a Companhia da Virginia 'limpará suas ruas e portas de crianças e desocupados, e lhes dará emprego: e, de fato, se todo o país fosse um Bridewell, para obrigar as pessoas a trabalhar, seria bom'. Ele queria que a América funcionasse como uma prisão, e para muitos é o que ela foi. ${ }^{23}$

Outro fator que impulsionou a chegada dos ingleses no Novo Mundo é a crescente tensão religiosa que se intensificou com a criação do anglicanismo por Henrique VIII. Devese ressaltar que a religião e o ethos puritano ${ }^{24}$, de uma maneira geral, acompanham o processo de colonização inglesa. Essa religião, fruto da Reforma Protestante, propõe, entre outras coisas, que através do trabalho e do acúmulo de capital adquire-se o reconhecimento divino. E, com isso, a ética do trabalho e um rígido código de conduta estarão presentes no dia-a-dia de muitos colonos norte-americanos.

Segundo Alexis de Tocqueville (1805-1859), o ethos puritano adquiriu tamanha importância na formação cultural dos Estados Unidos da América que, para além de uma doutrina religiosa, o puritanismo tomou ali o contorno de uma teoria política ${ }^{25}$. Max Weber, em “A ética protestante e o espírito do capitalismo”, também salientou sobre as possíveis relações de compatibilidade existentes entre a ética de vida puritana e o desenvolvimento do capitalismo nos Estados Unidos da América. Nesse sentido, é possível afirmar que o puritanismo foi um dos fatores que marcaram a formação político-cultural dos Estados Unidos e, assim sendo, o presente artigo busca investigar qual era, na visão de Goldman, a relação entre o puritanismo e outras esferas da vida.

\section{O puritanismo por Emma Goldman}

El puritanismo nos ha hecho tan egocéntricos e hipócritas por tanto tiempo, que la sinceridad y la veneración por ló que es natural en nuestros impulsos han sido limpiamente extirpadas de nosotros, com el resultado de que ya no puede haber ninguna verdad ni individualidad en nuestro arte. (Mr. Gutzon Borglum) ${ }^{26}$.

\footnotetext{
${ }^{22}$ Ibid., p.67.

${ }^{23}$ Ibid., p.69.

${ }^{24}$ Sobre o ethos puritano ver obra: WEBER, Max. "A ética protestante e o espírito do capitalismo". São Paulo: Martin Claret, 2013.

${ }^{25}$ Sobre a perspectiva elaborada por Tocqueville ver mais em: TOCQUEVILLE, Alexis de. "A democracia na América: Leis e Costumes". São Paulo: Martins Fontes, 2014. ; e TOCQUEVILLE, Alexis de. "A democracia na América: sentimentos e opiniões". São Paulo: Martins Fontes, 2014.

${ }^{26}$ Apud GOLDMAN, 2010, p.75.
} 
El puritanismo es la muerte de la cultura, la filosofia, el humor y la buena camaradería; sus características son la vulgaridade, la monotonia y la oscuridad. (Hippolyte Taine). ${ }^{27}$

Em "La Hipocresía del Puritanismo"28 Goldman discorreu sobre a influência do puritanismo em diferentes áreas da vida humana, isto é, ela investigou como o ethos puritano $^{29}$ impõe restrições ao livre desenvolvimento dos seres humanos. Ao analisar trajetórias de diferentes artistas, Goldman apontou que o puritanismo "forzó a algunas de lãs mujeres más libres de Inglaterra a incurrir en la mentira convencional del matrimonio: Mary Wollstonecraft y, posteriormente, George Elliot. Y más recientemente también exigió otra víctima: la vida de Oscar Wilde" ${ }^{30}$.

Segundo E.G., o ethos puritano chegou ao solo norte-americano em virtude do processo de colonização, pois, segundo ela, esse ethos foi "legado por nuestros padres fundadores" 31 e, significou, não raro, a transformação da vida "em tinieblas, la alegría en desesperación, lo natural em morbosa enfermedad, y la honestidad y la verdad em odiosas mentiras e hipocresías" ${ }^{32}$. Ao refletir sobre a violência explícita que envolveu as tentativas de incutir na sociedade os princípios morais do puritanismo, E.G. salientou que, diferente dos primeiros tempos da colonização, o puritanismo do século XX "no emplea el torniquete y la mordaza" mas, ainda sim, "sigue manteniendo una influencia cada vez más perniciosa en la mentalidad y sentimientos de los norteamericanos [grifo nosso]"33.

De fato, é possível afirmar que o ethos puritano, entre outras coisas, incidia fortemente sobre as mulheres, impondo-lhes certas premissas que, não raro, limitavam sua atuação social. Como exemplo dessa forte determinação que esse ethos tinha em relação à vida das mulheres,

\footnotetext{
${ }^{27}$ Apud GOLDMAN, 2010, p.81.

${ }^{28}$ No presente artigo utilizaremos a versão em espanhol do artigo originalmente denominado "The Hypocrisy of Puritanism". A versão utilizada pode ser encontrada no livro GOLDMAN, Emma. "La palavra como arma". Buenos Aires: Libros de Anarres; La Plata: Terramar, 2010.

${ }^{29}$ Como aponta Max Weber, na obra “A ética protestante e o espírito do capitalismo”, o puritanismo chegou, nos Estados Unidos, a modelar as condutas individuais fornecendo princípios éticos para o trabalho e a produção. E, como acrescenta Tocqueville, na obra “A democracia na América (...)”, a inserção do ethos puritano na sociedade estadunidense foi tão significativa que ali ele tornou-se uma teoria política. Nesse sentido, usamos o termo "ethos puritano", bem como "princípios morais puritanos" para remeter as premissas de conduta propostas por essa doutrina, muitas das quais, ao serem adotadas e legitimadas pela sociedade da época, limitaram a atuação social da mulher e significava, não raro, o controle da sociedade sob seus corpos.

${ }^{30}$ GOLDMAN, Emma. "La palavra como arma”. Buenos Aires: Libros de Anarres; La Plata: Terramar, 2010, p. 75.

${ }^{31}$ Ibid., p. 76.

${ }^{32}$ Idem.

${ }^{33}$ Idem.
} 
Anthony Comstock ${ }^{34}$, apresenta-se como um personagem que, em conjunto com a lei ${ }^{35}$, buscava controlar os corpos feminismos, restringindo-lhes o direito ao uso de métodos contraceptivos possuindo, como base para tal proposta, justificativas de cunho religioso, visto que tal ideia liga-se à questão religiosa na medida em que no âmbito da cristandade protestante (e católica) daquele período, o uso de contraceptivos não era prática permitida.

Goldman relacionou a influência que o puritanismo tinha na mentalidade da sociedade norte-americana com, por exemplo, a força que personagens políticos como Anthony Comstock acabaram adquirindo naquele contexto. Era, para E.G., devido a força do puritanismo, que a sociedade norte-americana naturalizava o fato de Anthony Comstock "se desliza en la vida privada de las personas, espiando sus intimidades más recatadas" ${ }^{\text {36 }} \mathrm{e}$ acrescenta que "Comstock es la grosera expresión del puritanismo que se injertó en la sangre anglosajona, y aun los más avanzados liberales no han podido emanciparse a sí mismos”37.

\section{Segundo Goldman:}

El arte, la literatura, el teatro, la privacidad del correo, de hecho, nuestros más íntimos gustos, están a merced de este inexorable tirano. Anthony Comstock, o cualquier outro policía ignorante, ha recibido el poder de profanar el genio, echar por tierra y mutilar la sublime creación de la naturaliza: el cuerpo humano. Los libros que versan sobre las cuestiones más vitales de nuestra vida, y buscan echar luz sobre los peligrosamente ocultados problemas, son legalmente tratados como ataques criminales, y sus infortunados autores arrojados em la cárcel o llevados a la desesperación y la muerte. ${ }^{38}$

Goldman, enquanto anarquista que era, defendia um tipo de individualidade muito específica $^{39}$, se declarando abertamente contrária as limitações impostas pelo Estado, pelo

\footnotetext{
${ }^{34}$ Anthony Comstock (1844-1915) foi um inspetor e político norte-americano dedicado a refletir sobre temas ligados a moralidade. Ademais, surgiu, naquele contexto, uma lei em sua homenagem, isto é, a lei federal que entrou em vigor, nos Estados Unidos, em março de 1873 e que, por sua vez, tornava ilegal qualquer material "imoral", o que incluía os métodos contraceptivos. Devido a tal legislação a ativista feminista Margaret Sanger (1879-1966) foi presa, como também foi E.G. em 1916, após atuar em defesa do livre acesso das mulheres a diferentes tipos de método contraceptivos.

${ }^{35}$ Dada a intensa campanha de Anthony Comstock contra o acesso das mulheres a métodos contraceptivos, visto que o próprio Comstock os consideravam obscenos e lascivos, em 1873, é criada a lei federal (o Ato de Comstock) que tornava ilegal não só a venda de materiais contraceptivos, como também a divulgação de informações em relação a temas ligados a saúde da mulher, entre os quais, estava o aborto.

${ }^{36}$ GOLDMAN, Emma. "La palavra como arma". Buenos Aires: Libros de Anarres; La Plata: Terramar, 2010, p. 76.

${ }^{37}$ Ibid., p.77.

${ }^{38}$ Ibid., p.80.

${ }^{39}$ Ver mais em: GOLDMAN, Emma. "O indivíduo, a sociedade e o Estado, e outros ensaios". São Paulo: Editora Hedra, 2007.
} 
Capital, bem como pelas premissas religiosas e culturais, no que se refere ao livre desenvolvimento das potencialidades humanas. Nesse sentido, afirmava que:

\begin{abstract}
Pero com el puritanismo vigilando la vida norteamericana, ninguna verdad ni sinceridad es posible. No hay nada más que la sordidez y la mediocridad para dirigir la conducta humana, coartando la expresión natural y sofocando nuestros mejores impulsos [grifo nosso]. El puritanismo em este siglo XX sigue siendo el peor enemigo de la libertad y de la belleza, como cuando por primeira vez desembarcó em Plymouth Rock. Repudia, como algo vil y pecaminoso, nuestros más profundos sentimientos; pero ignorando absolutamente las funciones de las emociones humanas, el puritanismo em sí es el creador de los más horribles vicios. ${ }^{40}$
\end{abstract}

No que diz respeito à interferência do ethos puritano no corpo humano e, principalmente, no corpo da mulher, E.G. destaca que "el espíritu del puritanismo ha pervertido la mente humana que ha perdido su capacidad para apreciar la belleza del desnudo, obligándonos a ocultar la forma natural con el pretexto de la castidad" 41 e continua "la propia castidad no es más que una imposición artificial a la naturaleza, evidenciando una falsa vergüenza frente al cuerpo humano" ${ }^{\prime 2}$.

Parte significativa da literatura de E.G. diz respeito a temáticas ligada as questões de gênero e, ao investigar as "castrações" que a moral puritana impunha as mulheres, Goldman declara que "el puritanismo, con su perversión del significado y función del cuerpo humano, particularmente con respecto a la mujer, la ha condenado al celibato o a la procreación indiscriminada de una especie enferma, o a la prostitución"43.

Ademais, Goldman afirma que a continência sexual que a sociedade impõe a mulher solteira - visto que, caso uma mulher solteira assumisse ter uma vida sexual ativa, ela rapidamente iria ser taxada como "perdida" e, com isso, sofreria diversos constrangimentos sociais - proporcionava grandes males, pois, segundo Goldman, tal continência sexual poderia gerar não só neurastenia, depressão, bem como "una gran variedad de trastornos nerviosos que conllevarán la disminución de la capacidad de trabajo, la limitación de la alegria por vivir, el insomnio y uma preocupación por los deseos y fantasias sexuales" ${ }^{\$ 4}$.

Com base na produção intelectual de Sigmund Freud (1856-1939), isto é, levando em consideração os estudos de Freud $^{45}$ sobre as relações existentes entre comportamento e

\footnotetext{
${ }^{40}$ GOLDMAN, Emma. "La palavra como arma”. Buenos Aires: Libros de Anarres; La Plata: Terramar, 2010, p. 77. neurologista. Nas palavras da própria: "Em Viena podia-se ouvir palestras interessantes sobre prosa e sobre
} 
sexualidade, E.G. salientou que, tal continência sexual que, por sua vez, era imposta as mulheres, ou seja, "el arbitrário y nocivo precepto de la total continência" 46 , explicava, em grande medida, "las desigualdades mentales de $\operatorname{los} \operatorname{sexos"47}$ e, aliás, acrescenta que "así lo cree Freud, que la inferioridad intelectual de muchas mujeres se debe a la inhibición que se les ha impuesto com el fin de la represión sexual" ${ }^{" 4}$. E sobre as consequências oriundas dessas "obrigações sociais" - neste caso, da continência sexual e do matrimônio - que o ethos puritano impõe as mulheres, Goldman aponta que:

\begin{abstract}
Habiendo así suprimido los deseos sexuales naturales de la mujer soltera, el puritanismo, por otro lado, bendisse a su hermana casada com una fecundidade prolífica en el matrimonio. De hecho, no sólo la bendisse, sino fuerza a la mujer, sexualmente obsesionada por la represión previa, a ter hijos, sin tener em cuenta su delicada condición física o incapacidade económica para mantener a uma família amplia. Los métodos preventivos, completamente prohibidos e, incluso, la simple mención de los mismos, se considera como um crimen ${ }^{49}$.
\end{abstract}

Dado o fato de que o ethos puritano, ao propor e, não raro, impor um "tipo ideal de mulher" - isto é, aquela que reproduziria todos os princípios que compõe a referida doutrina ele, neste sentido, reforça políticas conservadoras que, entre outras coisas, propõem o não acesso democrático a métodos contraceptivos, bem como a não legalização do aborto. Para E.G. "la ilimitada capacidad del puritanismo para hacer el mal se basa em su atrincheramiento tras el Estado y las leyes" $" 50$, pois, afinal "pretendiendo salvaguardar em la maquinaria gubernamental dándole el carácter de guardián moral de la censura legal de nuestros planteamientos, sentimientos e incluso nuestras conductas" $" 51$.

poesia alemãs modernas. Podia-se ler os trabalhos dos jovens iconoclastas na arte e na literatura, o maior ousado deles sem dúvida era Nietzsche. A mágica de sua linguagem e a beleza de sua visão levava-me a alturas sonhadas. Eu ansiava em devorar cada linha de seus escritos, mas era pobre demais para compra-los. Felizmente Grossmann tinha um suprimento de Nietzsche e outros modernos [...] Meu amigo me sugeriu que eu fosse às aulas do professor Bruhl, que também discutia problemas sexuais [...] A clareza quanto a esses assuntos foi muito maior quando ouvi Sigmund Freud. Sua simplicidade e sua franqueza, além do brilhantismo de sua mente combinavam-se para dar a sensação de ser levado de um porão escuro até a luz do dia. Pela primeira vez percebi o significado pleno da repressão sexual e de seus efeitos no pensamento e na ação humana. Ajudou-me a compreender, a compreender minhas necessidades; também percebi que apenas as pessoas mentes depravadas poderiam impugnar os motivos os crê-los 'impuros' numa personalidade tão grande quanto Freud.” GOLDMAN, Emma. "Vivendo minha Vida". Curitiba: L-Dopa Publicações, 2015. p.127.

${ }^{46}$ GOLDMAN, Emma. "La palavra como arma”. Buenos Aires: Libros de Anarres; La Plata: Terramar, 2010, p. 78.

${ }^{47}$ Idem.

${ }^{48}$ Idem.

${ }^{49}$ Idem.

${ }^{50}$ GOLDMAN, Emma. “La palavra como arma”. Buenos Aires: Libros de Anarres; La Plata: Terramar, 2010, p. 80.

${ }^{51}$ Idem. 
Pois bem, assim sendo, E.G. afirma sobre os casos de aborto que "teniendo en cuenta el secreto con que necesariamente se tienen que practicar, y las consecuencias de la ineficácia y negligencia professional, el puritanismo continuamente supone miles de víctimas por su propia estupidez e hipocresía" 52 . E sobre a relação existente entre a prática da prostituição que muitas mulheres são levadas a adotar - e o puritanismo, E.G. considera que a esse respeito "como único remedio, el puritanismo plantea frente a esta hija descarriada una gran represión y uma más despiadada persecución" 53 e, ademais, "el puritanismo busca ocultar el terrible azote que él mismo ha creado, las enfermedades venéreas" e, neste sentido, para E.G.:

\begin{abstract}
Lo más desalentador es este espíritu obtuso de cerrazón mental que ha emponzoñado a los denominados liberales, y los ha cegado para que se unan a la cruzada contra esta cosa nacida de la hipocresía del puritanismo: la prostitución y sus consecuencias. ${ }^{54}$
\end{abstract}

Por fim, para E.G., "todos los estímulos que excitan la imaginación y despiertan los espíritus son tan necesarios para nuestra vida com el aire. Estimulan el cuerpo, intensificam nuestros planteamientos de compañerismo humano" 55 , pois "sin estímulos, de uma u otra forma, el trabajo creativo es imposible, ni tampoco el espíritu de bondad y generosidad"56 e, neste sentido, para E.G. "el puritanismo, em cualquier expresión, es um germen venenoso. En la superfície puede parecer fuerte y vigoroso; sin embargo, el veneno trabaja persistentemente, hasta que toda la estructura es derribada" ${ }^{\text {. }}$.

\title{
Considerações finais
}

O presente artigo, levando em consideração a formação político-cultural dos Estados Unidos da América, buscou investigar, partindo do artigo "La Hipocresía del Puritanismo", qual era a interpretação da feminista e anarquista Emma Goldman (1869-1940) no que se refere à relação existente entre o ethos puritano e práticas ditas como cotidianas, bem como compreender de qual forma o puritanismo influenciou não só na formação da cultura política norte-americana, mas também na arte e nas medidas governamentais norte-americanas. Ademais, buscou-se, principalmente, analisar, qual era na perspectiva de E.G., o impacto da moral puritana no corpo e na vida das mulheres no início do século XX.

\footnotetext{
${ }^{52}$ Ibid., p. 79.

${ }^{53}$ Idem.

${ }^{54}$ Idem.

${ }^{55}$ GOLDMAN, Emma. "La palavra como arma”. Buenos Aires: Libros de Anarres; La Plata: Terramar, 2010, p. 80 .

${ }^{56}$ Idem.

${ }^{57}$ Idem.
} 


\section{Referências bibliográficas}

AVRICH, Paul. “The Haymarket Tragedy”. Princeton: Princeton University Press, 1986. BIANCHI, Bruna (epílogo) \& SHULAMAN. Alix Kates (prólogo). GOLDMAN, Emma. "La mujer más peligrosa del mundo: textos feministas de Emma Goldman”. Edición: La Congregación [Anarquismo em PDF], Portada: Reybum.

BLANCHETTE, Thaddeus. "Emma Vermelha e o espectro do tráfico de mulheres". Cad. Pagu [online]. 2011, n.37, pp. 284-297. ISSN 0104-8333. Disponível em: http://dx.doi.org/10.1590/S010483332011000200012. Acesso 10/06/2018.

GOLDMAN, Emma. "La palavra como arma". Buenos Aires: Libros de Anarres; La Plata: Terramar, 2010. . “O indivíduo, a sociedade e o Estado, e outros ensaios”. São Paulo: Editora Hedra, 2007.

"Vivendo minha Vida". Curitiba: L-Dopa Publicações, 2015.

HOBSBAWM, Eric. “A Era dos Extremos: O breve século XX (1914-1991)”. São Paulo: Companhia das Letras, 2015. 598 p

KRAUSE, Paul. "The battle for Homestead, 1880-1892: politics, culture, and steel". Pittsburgh: University of Pittsburgh Press, 1992. 584 p.

LINENBAUGH, Peter; REDIKER, Marcus. "A hidra de muitas cabeças: marinheiros, escravos, plebeus e a história oculta do Atlântico revolucionário". São Paulo: Companhia das Letras, 2008.

LOBO, Elisabeth Souza. "Emma Goldman - A vida como Revolução". São Paulo, Brasiliense, 1983.

MARTINS, Nilciana Alves. “A revolução Russa por Emma Goldman”. 2018. Trabalho de Conclusão de Curso [TCC]. Departamento de História da Universidade Federal de Juiz de Fora.

. “A Revolução Russa por Emma Goldman”. Aurora. 2018, n.1, pp.39-48. https://revistaurora.files.wordpress.com/2018/06/aurorav1n1_04_martins.pdf. $\quad$ Acesso: 08/02/2018.

. "Emma Goldman e Liév Trótsky: Uma Análise Comparada dos Discursos".

$\begin{array}{lllllll}\text { Cantareira } & \text { (UFF). } & \text { 2018, n.28, } & \text { pp. 161-171. ISSN } & \text { 1677-7794. }\end{array}$ http://www.historia.uff.br/cantareira/v3/?p=3852. Acesso: 08/02/2018. 
"Emma Goldman: Trajetória, Anarquismo e Feminismo". In: Encontro Internacional e XVIII Encontro de História da Anpuh-Rio: História e Parcerias, 2018, Niterói. Anais do Encontro Internacional e XVIII Encontro de História da Anpuh-Rio: História e Parcerias. Rio de Janeiro: Anpuh-Rio, 2018. Disponível em: https://www.encontro2018.rj.anpuh.org/resources/anais/8/1529783999 ARQUIVO ARTIGO ANPUH-RJNilcianaAlvesMartinsatualizado.pdf. Acesso: 08/02/2018.

MARX, Karl. "A Origem do Capital: a acumulação primitiva". São Paulo: Editora Global, 1977.

NIETZSCHE, Friedrich. “Além do bem e do mal”. São Paulo, Companhia de Bolso, 2005. PERROT, Michelle. “Os excluídos da História: operários, mulheres e prisioneiros”. Paz \& Terra, 2017.

RAGO, Margareth. "Prefácio à Emma Goldman: tráfico de Mulheres". Cad. Pagu [online]. 2011， n.37, pp.263-271. ISSN 0104-8333. http://dx.doi.org/10.1590/S010483332011000200010. Acesso: 12/11/2017.

RÉMOND, René. "Por uma história política". Rio de Janeiro: Editora FGV, 2003.

RICHTER, Liane Peters. "Emancipação feminina e moral libertária: Emma Goldman e Maria Lacerda de Moura". 1998. Dissertação de Mestrado. Departamento de História do Instituto de Filosofia e Ciências Humanas da Universidade Estatual de Campinas.

SCOTT, Joan Wallach. "Gênero: uma categoria útil de análise histórica”. Educação \& Realidade. Porto Alegre, vol. 20, $\mathrm{n}^{\mathrm{o}}$ 2, jul./dez. 1995, pp. 71-99. < https://repositorio.ufsc.br/bitstream/handle/123456789/1210/scott_gender2.pdf $>$. Acesso: $12 / 11 / 17$

SHULMAN, Alix Kates. "To the barricades: the anarchist life of Emma Goldman". New York: Crowell, 1971.

TOCQUEVILLE, Alexis de. "A democracia na América: Leis e Costumes". São Paulo: Martins Fontes, 2014.

"A democracia na América: sentimentos e opiniões". São Paulo: Martins Fontes, 2014.

WEBER, Max. "A ética protestante e o espírito do capitalismo". São Paulo: Martin Claret, 2013. 